\title{
SOCIO-ECO-EFFICIENCY ANALYSIS OF HIGHWAYS: A DATA ENVELOPMENT ANALYSIS
}

\author{
Omer TATARI ${ }^{\mathrm{a}}$, Gokhan EGILMEZ ${ }^{\mathrm{b}}$, Dhruva KURMAPU ${ }^{\mathrm{c}}$ \\ ${ }^{a}$ Department of Civil, Environmental, and Construction Engineering, University of Central Florida, \\ Orlando, FL 32816, USA \\ ${ }^{b}$ Department of Industrial and Manufacturing Engineering, North Dakota State University, ND 58102, USA \\ ${ }^{c}$ Department of Industrial and Systems Engineering, Ohio University, OH 45701, USA
}

Received 05 Jul 2012; accepted 04 Sep 2013

\begin{abstract}
To ensure the large network of highways is performing sustainably, there is a dire need to quantify sustainability for highways. In this paper, data envelopment analysis (DEA) based mathematical model is developed to evaluate sustainability in an attempt to aid these efforts. Sustainability goals pertaining to the three dimensions of sustainability, social, economic and environmental, were utilized. Utilizing the developed model, sustainability scores of thirty highway sections were calculated and ranked accordingly. Percent improvement analysis was carried out to gain more insight. In addition, sensitivity analysis was carried out to understand how different values of input parameters impacted the socio-eco-efficiency of each highway section. The aim of the study was to show that DEA based sustainability assessment model could be used to evaluate highways and assist in strategic planning goals of transportation agencies. Results indicated that $22 \%$ to $47 \%$ reductions are required to be achieved on negative social and environmental impacts for the inefficiency highway sections to be $100 \%$ efficient while keeping the economic indicators the same.
\end{abstract}

Keywords: data envelopment analysis, sustainable development, socio-eco-efficiency, highways.

\section{Introduction}

Rising urbanization worldwide brings challenging problems to governments and stakeholders thus societies due to the fact that more and more people migrate to urban areas and projections indicate that more than $60 \%$ of world population will be living in the urban areas by 2030 (Shcherbakova 2010). In fact, the rapidly increasing trend in urban growth causes similar pattern of behavior in transportation activities. Therefore, roads of the urban areas become an integral element of sustainable development. If societies and governments fail to develop economically viable, socially acceptable and environmentally benign strategies to stabilize the worsening trends, significant amount of the carrying capacity of earth will be lost, which is expected to cause severe problems worldwide. In this regard, since highways are the principle means of transportation in urbanized areas, sustainability assessment initiatives have to be taken towards decreasing social and environmental problems that come along with and increasing the economic outputs in this problem domain as well.

The United States has the world's largest and busiest network of highways (USDOT 2008). Maintaining this vast system while maximizing user safety and mini- mizing its environmental impact is of critical importance. To ensure the highways are performing to this ability, there is a dire need to quantify sustainability for highways. The vital need for sustainability metrics has been acknowledged by the Nation's leading scientific and industrial organizations. For instance, the need for a scientific evaluation framework for evaluating and integrating the life cycle environmental and economic performance of the nation's infrastructure has also been emphasized as a critical research agenda by the National Science and Technology Council (2008). Yet, there are many challenges related to quantifying the abstract concept of sustainability of highways. There is still a lack of a standard methodology for sustainability evaluation (López, Monzón 2010). The primary difficulty lies in objectively evaluating environmental, social, and economical dimensions and the sub-categories within each dimension.

Several studies have been conducted to evaluate highway sustainability utilizing multi-criteria decision making (MCDM) approaches. Jeon et al. (2007) applied MCDM approach to evaluate transportation and land use plans in the Atlanta region in terms of comprehensive sustainability parameters. Ramani et al. (2008) utilized Multi-Attribute Utility Theory methodology to evaluate

Corresponding author: Omer Tatari

E-mail: tatari@ucf.edu 
sustainability. The way how multi-criteria evaluation approaches tackle the sustainability assessment problem is that they combine information from several criteria so as to form a single index of evaluation, which is mostly proposed as a function which is based on assignment of subjective weights by experts. Therefore, such approaches are based on expert judgment.

Most studies combine different aspects of sustainability by introducing subjective weightings or assigning equal weights to all criteria considered in their sustainability framework (Amekudzi et al. 2009; Ramani et al. 2008). Yet, there is neither a consensus nor a satisfactory method to guide the assignment of weightings (Ding 2008). Thus, a theoretical framework which does not require $a$ priori determined weightings might be useful in determining a single score for sustainability. Data envelopment analysis (DEA), a linear programming based mathematical modeling approach, could be a good candidate to accomplish this task, since it does not require the use of subjective weightings to rank the sustainability scores of highway sections. This methodology has already been used by several researchers in similar studies. Färe et al. (2004) provided a formal index number that can be computed using DEA techniques. Kuosmanen and Kortelainen (2005) used DEA approach to assess eco-efficiency of road transportation in Finland. Ozbek et al. (2010) used data envelopment analysis to measure the overall efficiency of road maintenance operations while considering the effects of environmental and operational factors on the overall efficiency.

The objective of this paper is to develop an analytical tool that can be used to benchmark the sustainability performance of highways utilizing DEA. Performance Indicators of highways are used to derive sustainability ratios and DEA is used to rank the highway sections with respect to sustainability, accordingly. The rest of the paper is organized as follows. First, the methodology is presented. Results and discussion are then presented. Finally, the findings are summarized and limitations and future work are pointed out.

\section{Methodology}

The methodology of the study is broken into four steps. First, we derive sustainability score in a ratio format. Second, we select the appropriate economic, social and environmental indicators. Third, we collect the appropriate data from the public records of Oregon Department of Transportation. Lastly, we develop the appropriate DEA models for the current study.

\subsection{Derivation of sustainability ratio}

Highway sustainability has been used to refer to maximizing the highway system's quality of service while minimizing its potential adverse effects on sustainability (Ramani et al. 2008). It has mostly been analyzed using three dimensions, the triple bottom line; economic, environmental, and social equity (Barbier 2009; Graedel,
Allenby 2009; Mihelcic et al. 2003). Literature on transportation sustainability has focused on these three dimensions of sustainability, as well (Hall 2006; Johnston 2008; Litman 2005, 2007; Richardson 2005). Many indicators have been proposed to measure these three dimensions. For instance, Litman (2007) and Jeon and Amekudzi (2005) provided an extensive list of indicators that pertain to transportation sustainability dimensions. On the other hand, Ramani et al. (2008) identified five goals to reach highway sustainability: reduce congestion, enhance safety, expand economic opportunity, improve air quality, and increase the value of transportation assets. Similarly, Richardson (2005) identified five major areas that need to be monitored for more sustainable highways: safety, congestion, fuel consumption, vehicle emissions, and access.

While many indicators have been suggested to be included in the assessment of highway sustainability, different strategies have been utilized to combine the indicators to arrive at a single sustainability score. Typically, the sustainability score is derived by adding the weighted index values of the indicators from each impact category (e.g. economic, social impacts) into a composite sustainability index (Jeon et al. 2007):

$$
U_{i}=\sum_{j=1}^{n}\left(w_{j}^{*} r_{i j}\right),
$$

where the sustainability score is conceptualized as the weighted $\left(w_{j}\right)$ average of the indicators $(j)$ considering the impacts $\left(r_{i j}\right)$ three sustainability dimensions $(i)$. In this regard, economic value added is the economic benefits of the system or unit analyzed. While this approach is successful in deriving a single score, it does not capture the balancing relationship between these indicators and the weight assignment is bias where priorities might change among different stakeholders. The sustainability score is often determined with respect to economic, social and environmental impacts. Economy is an important pillar for sustainable development of our nation so that the transportation systems. Therefore, the economic indicators of a transportation system is directly associated with their potential impact on expanding the economic opportunity for a nation. Towards improving economic dimension of sustainable development, the indicators that increase the economic growth directly or indirectly are desired to be maximized. Besides, social impacts of transportation activities can be also refer to the characteristics that can improve the travelers' safety and mobility (e.g. travel time, traffic crashes, etc. In this context, minimizing the negative social impacts such as travel time, traffic crashes can have a considerable impact on the sustainability performance. And, the environmental impacts such as air pollution also need to be included in assessing the sustainability score to do a comprehensive sustainability performance assessment.

With regards to the environmental impacts, for instance, a busier highway might result in higher emissions, and the sustainability score needs to accurately represent 
the proportion of these emissions with respect to the highway load. And the direction of improvement should be towards minimizing such negative impacts to increase the sustainability performance. Conversely, in this study, following Callens and Tyteca (1999), the sustainability score is developed by taking the ratio between economic impacts, and the social and environmental impacts:

\section{Highway Sustainability score $=$ Economic Impacts \\ Social and Environmental Impacts}

The derived sustainability ratio can also be termed as the socio-eco-efficiency of highways. In fact, this term is often addressed in sustainability literature to represent how efficient a decision making unit is in terms of the overall sustainability performance considering the social, economic and environmental aspects. While eco-efficiency analysis analyzes sustainability performance of a DMU based on economic benefits and environmental impacts (Tatari, Kucukvar 2012); socio-eco-efficiency extends the eco-efficiency concept to the triple bottom-line sustainability score by including the social aspects of sustainability performance. The ratio approach helps to evaluate maximization of the positive economic impacts while minimizing the negative social and environmental impacts.

This sustainability ratio is based on the eco-efficiency concept, which has emerged as an alternative tool to combine environmental and economic performance indicators. Eco-efficiency ratio focuses on delivering competitively priced goods and services that satisfy human needs and enhance the quality of life, while making the efforts to reduce the environmental and ecological impacts throughout product life cycles (Kibert, 2008). It is a concept that can provide a useful framework which includes most of the principles of sustainable development to aid in decision making for infrastructure projects. Eco-efficiency analysis has been used successfully as a valuable assessment tool towards the target of sustainable development (Barba-Gutiérrez et al. 2009; Korhonen, Luptacik 2004; Kuosmanen, Kortelainen 2005).

\subsection{Selection of operational variables}

The most common goals cited in the literature that address the three dimensions of sustainability were utilized in this study: improve freight transport, maintain highway system quality, improve mobility, improve safety, reduce adverse human health impacts, and reduce greenhouse effect (see Table 1). Although some of these objectives could be categorized under more than one sustainability dimension, the most dominant one is chosen. For each particular objective, one measurable indicator was selected based on the literature (Jeon et al. 2007; Litman 2007; Ramani et al. 2008; Richardson 2005).

In terms of economic indicators, expanding economic opportunity and increasing the value of transportation assets could be achieved by improving the road based freight movement and maintaining the quality of the existing highway system. To measure these objectives, truck throughput efficiency (TTE) and average pavement condition (APC) score are utilized, respectively. Freight movement is a key economic benefit of highways and hence needs to be maximized. Truck throughput efficiency measures truck volumes and speeds as an output combination as shown in Eqn (3):

$$
\begin{aligned}
\mathrm{TTE}= & \text { Daily truck volumes per lane } \times \\
& \text { Truck operational speed. }
\end{aligned}
$$

APC score measures the quality of maintenance of a section of the highway road, and gives a good indication regarding the value of transportation assets. APC is scaled between 0 and 100, as a road condition score which is a combination of various factors including surface distress, rutting, and ride quality. APC scores are directly obtained from Oregon DOT's databases.

Reducing congestion and enhancing safety by improving mobility on highways and reducing crash rates and crash risk are chosen as key indicators to measure the social impact of the highways. Travel time index (TTX) and annual severe crashes per mile are utilized as the respective performance indicators. TTX measures the extent of delays caused in travel due to traffic congestion

\begin{tabular}{|c|c|c|c|c|}
\hline Dimension & Objective & Indicator & Acronym & References \\
\hline \multirow{2}{*}{ Economic } & Improve freight transport & $\begin{array}{l}\text { Truck throughput } \\
\text { efficiency (mph) }\end{array}$ & TTE & Litman (2007), Ramani et al. (2008) \\
\hline & Maintain highway system quality & Pavement condition score & APC & Litman (2007), Ramani et al. (2008) \\
\hline \multirow{2}{*}{ Social } & Improve mobility & Travel time index & TTX & $\begin{array}{l}\text { Jeon et al. (2007), Ramani et al. } \\
\text { (2008), Richardson (2005) }\end{array}$ \\
\hline & Improve safety & Annual crashes/mile & $\mathrm{ACM}$ & $\begin{array}{l}\text { Jeon et al. (2007) Ramani et al. } \\
\text { (2008), Richardson (2005) }\end{array}$ \\
\hline \multirow{3}{*}{ Environmental } & $\begin{array}{l}\text { Reduce adverse human health } \\
\text { impacts }\end{array}$ & $\begin{array}{l}\mathrm{NO}_{\mathrm{x}}, \mathrm{CO}, \text { and } \mathrm{VOC}^{*} \\
\text { emissions }(\mathrm{mT})\end{array}$ & $\mathrm{NCV}$ & $\begin{array}{l}\text { Jeon et al. (2007), Ramani et al. } \\
\text { (2008), Richardson (2005) }\end{array}$ \\
\hline & Reduce greenhouse effect & $\begin{array}{l}\text { Daily } \mathrm{CO}_{2} \text { emissions } \\
(\mathrm{mT})\end{array}$ & $\mathrm{CO} 2$ & $\begin{array}{l}\text { Jeon et al. (2007), Ramani et al. } \\
\text { (2008), Richardson (2005) }\end{array}$ \\
\hline & Reduce traffic noise & $\begin{array}{l}\text { Average noise level } \\
(\mathrm{dBA})\end{array}$ & ANL & $\begin{array}{l}\text { Jeon et al. (2007), Ramani et al. } \\
\text { (2008), Richardson (2005) }\end{array}$ \\
\hline
\end{tabular}

Table 1. Selected highway sustainability objectives and indicators 
alone and annual severe crashes per mile measures the crash rate on highways. In this context, TTX is preferred to be used as congestion related performance indicators since it has been widely applied in various institutional reports related to congestion. TTX is calculated via Eqn (4) (Ramani et al. 2008):

$$
\begin{aligned}
& \text { Travel Time Index }(\text { TTX })= \\
& \frac{\text { Peak Hour Travel Rate }(\text { Minutes per Mile })}{\text { Travel Rate at Posted Speed Limit }} .
\end{aligned}
$$

The peak hour travel rate is calculated by using the procedure provided in TTI's Urban Mobility Report (Schrank, Lomax 2009). The procedure determines the peak-period vehicle operating speeds based on the average daily traffic (ADT) per lane. The peak period speed guidelines are provided in Table 2.

Table 2. Peak period speed guidelines

\begin{tabular}{ll}
\hline \multicolumn{1}{c}{ ADT per lane } & \multicolumn{1}{c}{ Peak period speed $(\mathrm{PPS})$} \\
\hline $15001-17500$ & $\mathrm{PPS}=70-(0.9 *$ ADT/lane $)$ \\
\hline $17501-20000$ & $\mathrm{PPS}=78-(1.4 *$ ADT $/$ lane $)$ \\
\hline $20001-25000$ & $\mathrm{PPS}=96-(2.3 *$ ADT/lane $)$ \\
\hline ADT/lane $>25000$ & $\mathrm{PPS}=76-(1.46 *$ ADT/lane $)$ \\
\hline
\end{tabular}

On the other hand, improving air quality, conserving natural resources and reducing traffic noises are chosen as key indicators to measure the environmental impacts of highways. Daily $\mathrm{NO}_{\mathrm{x}}, \mathrm{CO}$ and $\mathrm{VOC}$ emissions per mile of the highway, daily $\mathrm{CO}_{2}$ emissions per mile of highway and average noise level (ANL) are utilized as the respective performance indicators. $\mathrm{NO}_{\mathrm{x}}, \mathrm{CO}$ and VOC are weighted according to their relative damage costs in terms of human health impacts. $\mathrm{CO}_{2}$ emission is associated with global warming and it is measured in grams per mile of highway. ANL values are calculated as follows.

The average noise levels (ANLs) on the selected highways were calculated iteratively by using Eqns (5)(7) (Abbott, Nelson 2002). In this regard, first the basic road noise level is predicted (Eqn (5)). Then, the correction factor for traffic speed, percent of heavy vehicles and gradient is calculated (Eqn (6)). Finally, the impact of road surface on the road noise levels was captured with Eqn (7). The overall noise level prediction is performed by considering traffic speed, percent of heavy vehicles and road surface impact. Due to macro level data availability issues, the effect of gradient and other road characteristics such as size of size of segments, site layout are neglected:

$$
L_{10}(18 h r)=29.1+10 * \log _{10}(Q), d B A,
$$

where $Q$ is the 18 -hour traffic flow (vehicles/hour) with assumption of $V=75 / \mathrm{km} / \mathrm{h}$, percentage of heavy vehicles $p=0$ and gradient is zero $(G=0)$.

Correction for mean traffic speed, percentage of heavy vehicles and gradient:

$$
\begin{aligned}
& \Delta_{p V}=33 * \log _{10}\left(V+40+\frac{500}{V}\right)+ \\
& 10 * \log _{10}\left(1+\frac{5 p}{V}\right)-68.8, \mathrm{dBA} .
\end{aligned}
$$

The percentage of heavy vehicles is given by $p=\frac{100^{*} F}{Q}$, where $F$ is the 18 -hour flow of heavy vehicles. Moreover, road surface impact is calculated as follows:

$$
\Delta_{T D}=10 * \log _{10}(20 * T D+60)-20, \mathrm{dBA},
$$

where $T D$ is the texture depth.

\subsection{Data collection}

Highway sections were selected as the functional unit to carry out the study. Primarily, I-5, I-82, I-84, I-105, I-205, I-405 interstate highways were considered as the scope of the study, which serves to the vast majority of the traffic in the state of Oregon. Public data sources in the Oregon Department of Transportation (ODOT) website were used to collect data for thirty interstate highway sections (2010) which have an average of 5.93 miles length. Six indicators were utilized for sustainability measurement (see Table 3). TTX for each highway section was calculated based on Texas Transportation Institute's Urban Mobility Report (Schrank, Lomax 2009). Data for annual crashes per mile were gathered from ODOT's crash rate tables (ODOT 2008). TTE was calculated using equations from Ramani et al's study (2008). Truck volume was gathered from ODOT's traffic volume and vehicle classification online database. Average pavement condition data was extracted from ODOT's website. National Mobile Inventory model (NMIM) software was used to calculate $\mathrm{CO}_{2}, \mathrm{CO}, \mathrm{NO}_{\mathrm{x}}$, and VOC emissions for the highway sections. $\mathrm{CO}, \mathrm{NO}_{\mathrm{x}}$, and $\mathrm{VOC}$ emissions were weighted according to their relative damage costs in terms of human health impacts based on U.S. DOT's report on highway economic requirements system (Ramani et al. 2008; USDOT 2002). Noise data is obtained via using Eqns (5)-(7) and average traffic speed, daily traffic and road surface data obtained from ODOT's traffic volume and vehicle classification online database.

\subsection{Utilizing DEA models for evaluating highway sections}

The socio-eco-efficiency ratios were calculated for each highway section by utilizing DEA. DEA is a non-parametric method that got its birth from the work of Charnes, Cooper and Rhodes (1978). It is a linear programmingbased methodology that measures the relative efficiency of multiple Decision Making Units (DMUs) when there are multiple inputs and multiple outputs with different units (Sarkis 2007). DMUs are directly compared against peers or a combination of peers. DEA assesses how well a DMU is performing compared to other DMUs, by max- 


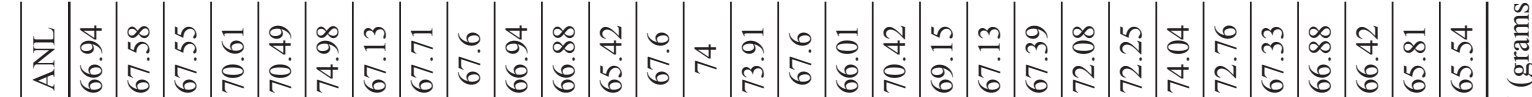
哥 可 z

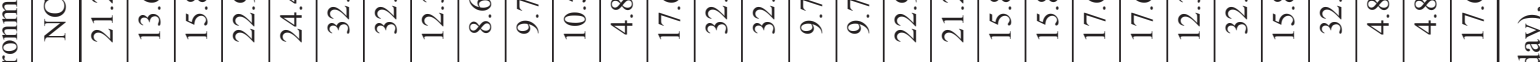

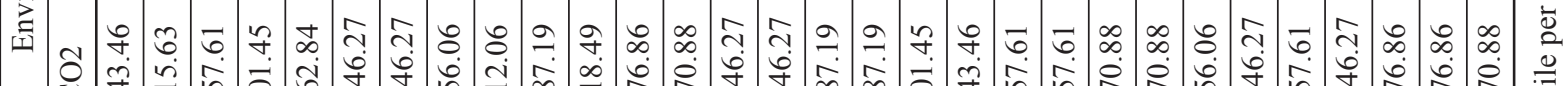

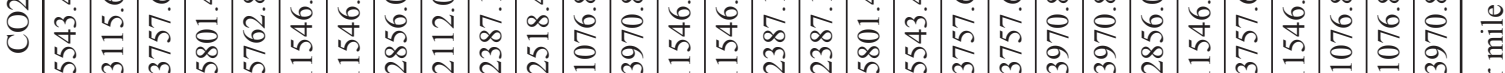

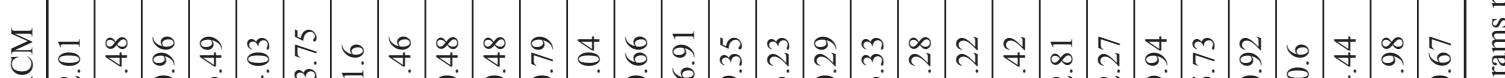
.]

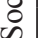

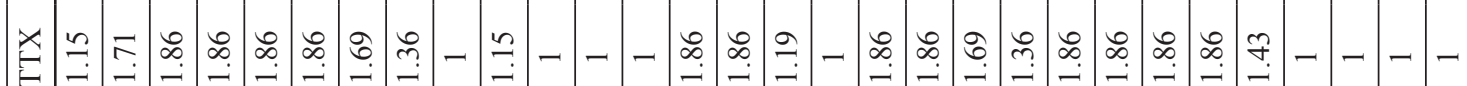

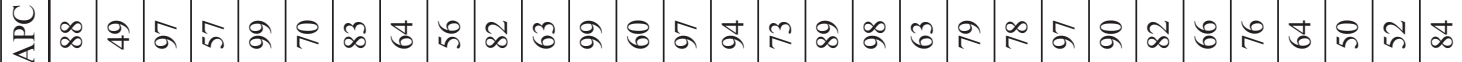
蒫

b) 背

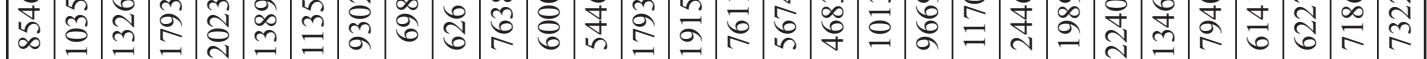


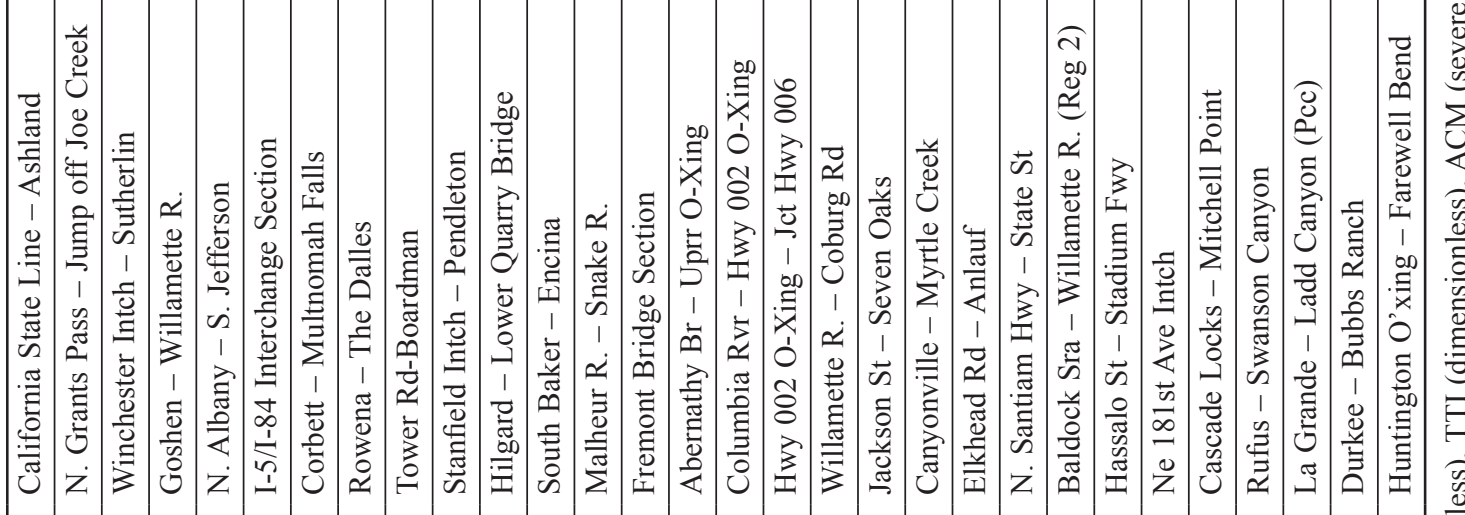
目

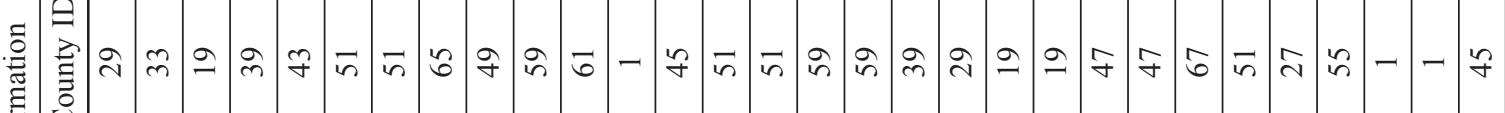
:

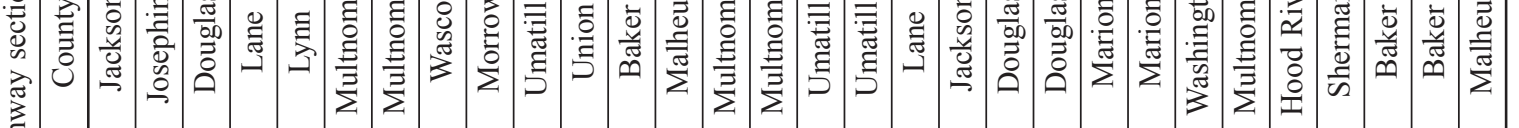
$\underbrace{3}_{0.0}$

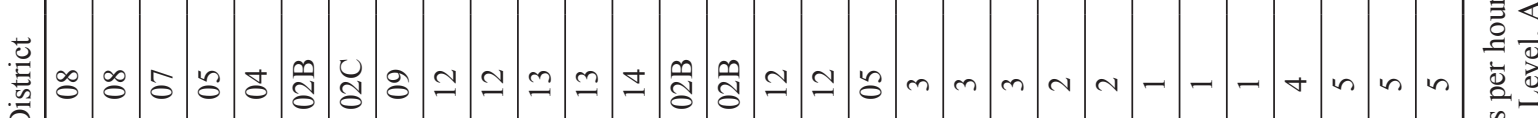

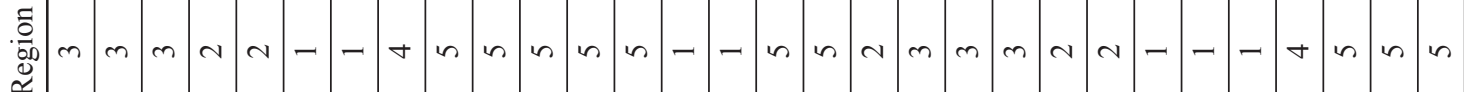
$\frac{\omega}{3} \cdot \frac{n}{0}$ $\underset{\vec{c}}{\vec{\tau}}$

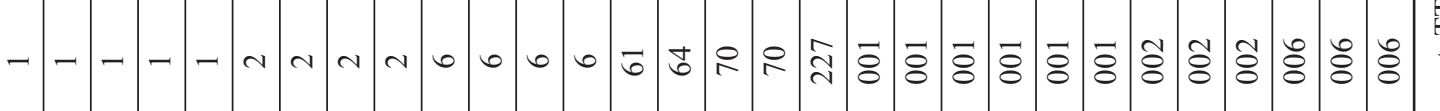
牙蛋 
imizing the output or minimizing the input of the studied DMUs. The basic concept of efficiency measurement was originally developed based on the ratio of total outputs to total inputs.

An example is provided below (see Table 4) to illustrate the basic concept behind DEA methodology. Suppose that there are three companies to be compared among each other based on how efficiently they produce total economic output (total outputs) from the total fixed and working capitals (total inputs). The economic value added per capital invested ratios simply represents their efficiency measurements where company A performs the best compared to others and is on the efficiency frontier. Therefore, setting company A's performance efficiency at $100 \%$, the remaining two companies' efficiency scores become $94.3 \%$ and $75.0 \%$.

Table 4. Efficiency score example

\begin{tabular}{ccccc}
\hline \multicolumn{5}{c}{ Performance of three companies } \\
\hline Company & $\begin{array}{c}\text { Total } \\
\text { inputs }\end{array}$ & $\begin{array}{c}\text { Total } \\
\text { outputs }\end{array}$ & $\begin{array}{c}\text { Economic value } \\
\text { added } \\
\text { per capital } \\
\text { invested }\end{array}$ & $\begin{array}{c}\text { Efficiency } \\
\text { score }\end{array}$ \\
\hline A & 120 & 140 & 1.17 & $100.0 \%$ \\
\hline B & 100 & 110 & 1.10 & $94.3 \%$ \\
\hline C & 80 & 70 & 0.88 & $75.0 \%$ \\
\hline
\end{tabular}

DEA models can primarily be grouped into two categories; one that has constant returns to scale and another that has variable returns to scale. The constant returns to scale based linear program equation, coined by Charnes et al. (1978), is as follows:

subject to:

$$
\max z=\sum_{r=1}^{s} \mu_{r} y_{r o}
$$

$$
\begin{aligned}
& \sum_{i=1}^{m} v_{i} x_{i o}=1 ; \\
& \sum_{r=1}^{s} \mu_{r} y_{r j}-\sum_{i=1}^{m} v_{i} x_{i j} \leq 0 \quad j=1, \ldots, n ; \\
& \mu_{r}, v_{i} \geq 0,
\end{aligned}
$$

where $\mu_{r}$ is the output multiplier, $v_{i}$ is the input multiplier, $o$ is the DMU under evaluation, $s$ represents the number of outputs, $m$ represents the number of inputs, $n$ represents the number of decision making units, $y_{r j}$ represents the amount of output $r$ produced by $\operatorname{DMU} j$, and $x_{i j}$ represents the amount of input $i$ used by DMU $j$. The objective function $z$ is the weighted sum of outputs for the DMU under evaluation.

A DEA model works by running the linear programming model for each DMU so as to compare one with the rest of the DMUs. The DMU with the maximum output and minimum input is considered as on the efficiency frontier based on which other DMUs' efficiency scores were relatively determined. The variable returns to scale
(VRS) based linear program equation, coined by Banker et al., is as follows (1984):

$$
\max z=\sum_{r=1}^{s} \mu_{r} y_{r o}+w
$$

subject to:

$$
\begin{aligned}
& \sum_{i=1}^{m} v_{i} x_{i o}=1 \\
& \sum_{r=1}^{s} \mu_{r} y_{r j}-\sum_{i=1}^{m} v_{i} x_{i j}+w \leq 0 ; j=1, \ldots, n \\
& \mu_{r}, v_{i} \geq 0
\end{aligned}
$$

where $\mu_{r}$ is the output multiplier, $v_{i}$ is the input multiplier, $o$ is the evaluated DMU, $s$ represents the number of outputs, $m$ represents the number of inputs, $n$ represents the number of decision making units, $y_{r j}$ represents the amount of output $r$ produced by DMU $j, x_{i j}$ represents the amount of input $i$ used by DMU $j$ and $w$ is the scale weight. The objective function $z$ is the weighted sum of outputs for the DMU under evaluation. In addition, $w$ represents the dual form of convexity constraint of inputoriented envelopment model (Thanassoulis 2001).

DEA model may take different forms by manipulating the objective function and adding different restrictions. It is critical to choose the suitable DEA model for the purpose of the study. The complexity that lies within DEA is to accurately select the right DEA strategy. This strategy depends on whether the studied phenomena can be modeled as a constant return to scale or variable return to scale. In VRS, the output does not increase by the same proportional change for each proportional increase in the input. On the other hand, CRS is a special case of the variable returns to scale in which the output increases by the same proportional change for each proportional increase in the input (Ozbek et al. 2010). Figure 1 illustrates the difference between CRS and VRS. From the CRS perspective, if the efficiency frontier is set based on company A, then even though companies $\mathrm{B}$ and $\mathrm{C}$ performs well depending on their greater input scales, their relative efficiency value are going to be far lower than the $100 \%$. To prevent this scale effect on efficiency scores, the variable returns to scale (VRS) property was included in DEA models so as to take scale difference into consideration.

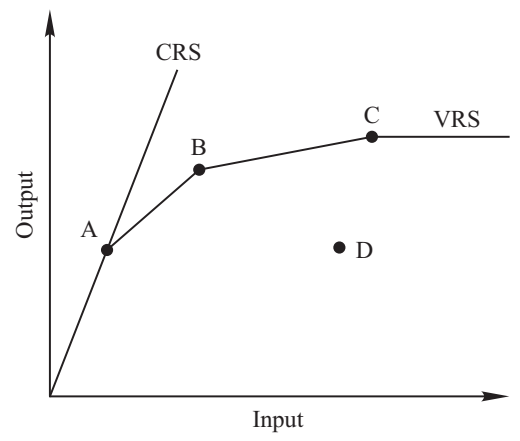

Fig. 1. CRS vs. VRS efficiency 
Once the type of the model is selected it is necessary to decide on the orientation (i.e. input oriented or output oriented). This decision is based on whether we want the input reduced or the output increased in the process.DEA methodology has been utilized by several researchers to evaluate the environmental performance of DMUs. Typically, environmental indicators have been considered as either undesired inputs or outputs in the DEA framework (see Färe et al. 1989; Tyteca 1997). On the other hand, Kuosmanen and Kortelainen (2005) utilized DEA approach to assess eco-efficiency of road transportation in Finland. Their approach deviated from the typical DEA approaches that have analyzed environmental impacts as secondary inputs or outputs. Instead, input and outputs that are not in direct interest in the framework were omitted. Callens and Tyteca (1999) and Tyteca (1999) utilized DEA to account for economic, social, and environmental indicators. In this approach, the indicators are utilized to compare DMUs that produce similar products within a specified time period. Indicators that should be minimized or maximized in order to reach sustainable efficiency are chosen. In this approach, undesirable inputs or outputs are minimized against the desirable inputs or outputs. This approach has been adopted for the current study and applied to the context of highway sustainability.

The general DEA framework in modeling the socio-eco-efficiency of highways is as follows: Social and environmental indicators act as inputs and economic indicators act as outputs. The DMU is represented as a highway section, where for each section there are two outputs and four inputs. The representation of highway sections as DMUs is similar to the study that was conducted by Cook et al. (2001). Triantis (2004) surveys the engineering applications of DEA, where DMU has been defined more appropriately as the unit of analysis in the engineering context. VRS approach was chosen for the current study, since there are large differences in the ADT and truck throughput between highway sections that are assumed to have non-constant return to scale with respect to the environmental and social indicators. This approach accounts for possible scale diseconomies that can exist between highways in different regions. Based on Eqn (7), the developed DEA model at time $t$ is as follows:

$$
\max z=a \mathrm{TTE}_{o}+b \mathrm{APC}_{o}+w,
$$

subject to:

$$
\begin{aligned}
& c \mathrm{TTI}_{o}+d \mathrm{ACM}_{o}+e \mathrm{NCV}_{o}+f \mathrm{CO} 2_{o}=1 ; \\
& \left(a \mathrm{TTE}_{j}+b \mathrm{APC}_{j}\right)- \\
& \left(c \mathrm{TTI}_{j}+d \mathrm{ACM}_{j}+e \mathrm{NCV}_{j}+f \mathrm{CO} 2_{j}\right)+w \leq 1, \\
& j=1, \ldots, n ; \\
& a, b, c, d, e, f \geq 0,
\end{aligned}
$$

where $a, b, c, d, e$, and $f$ are weights that are determined by the solution of model, $w$ is the scale weight, $o$ is the DMU which is being evaluated, $n$ is the number of DMUs, and TTE, APC, TTI, ACM, NCV, and $\mathrm{CO} 2$ represent the corresponding indicator values for each DMU. The above LP model was solved eighteen times; one for each DMU. For each DMU, the LP searches for a linear combination of other highway sections in the sample to produce a greater level of output with fewer inputs.

\section{Results and discussion}

Figure 2 shows the results of benchmarking model in terms of socio-eco-efficiency scores in percentages. The socio-eco-efficiency scores for the highway sections ranged from 0.65 to 1 . Results indicated that only nine highway sections (HS-30, HS-3, HS-22, HW-5, HS-29, HS-24, HS-9, HS-12 and HS-17) were found to have $100 \%$ socio-eco-efficiency score compared to the other highway sections. HS-25 was found to be the least efficient $(65 \%)$. The average efficiency score is obtained as $86.5 \%$ with a standard deviation of $12.2 \%$.

Although, it is important to evaluate the relative socio-efficiency of the highway sections with the pro-
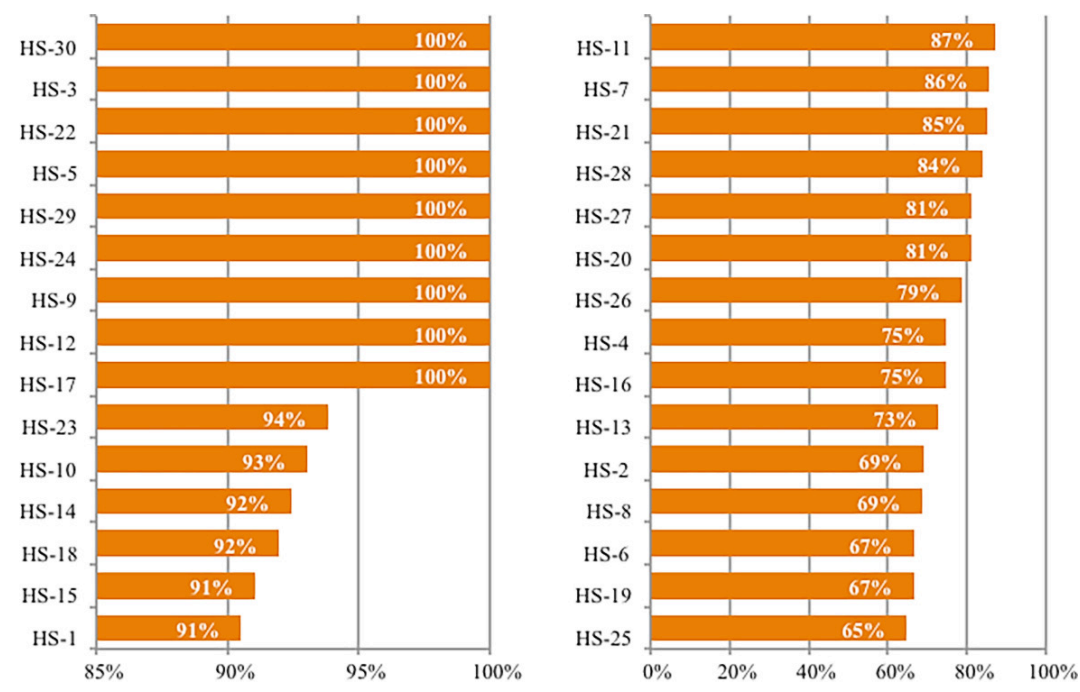

Fig. 2. Socio-economic efficiency scores 
posed linear programming-based benchmarking model, there is a need to quantify the potential improvements that can be achieved by inefficient highways to be $100 \%$ efficient. For inefficiency highway sections, the potential improvements can be achieved via reducing the negative environmental and social impacts while keeping the economic outputs the same. Table 5 shows the percent reductions in five input variables for each highway section to become $100 \%$ efficient. For instance, for HS-23 to reach $100 \%$ efficiency, it needs to reduce TTX by $6.2 \%$, ACM by $53.2 \%, \mathrm{CO}_{2}$ by $7.5 \%$, NCV by $8.9 \%$ AND ANL by $6.2 \%$. It is worth to note that HS-18 (46.8\%), HS-2 (39.3\%), and HS-25 (35.2\%) required the greatest reductions in TTX. For ACM, HS-6 (83.1\%), HS$14(79.0 \%)$ and HS-18 (69.1\%) required the highest amounts of reductions. For CO2, HS-27 (83.7\%), HS-18 (81.6\%), and HS-1 (73.6\%); for NCV HS-18 (79.1\%), HS-27 (76.0\%), and HS-1 (69.2\%) and for ANL, HS-28 (44.8\%), HS-2 (42.4\%) and HS-25 (35.2\%) required the highest amounts of reductions. It is important to note that the nine efficient highway sections mentioned above did not need any improvement in reducing their social and environmental indicators, since they were found to have $100 \%$ efficiency score.

Finally, a sensitivity analysis also conducted to evaluate the impact of each input variable on the socio-economic efficiency score. Figure 3 presents the sensitivity of each input indicator on the socio-eco-efficiency of inefficient highway sections along with the average tar-

Table 5. Target reductions in input variables (\%)

\begin{tabular}{lccccc}
\hline Highway & TTX & $\mathrm{ACM}$ & $\mathrm{CO}_{2}$ & $\mathrm{NCV}$ & $\mathrm{ANL}$ \\
\hline HS-23 & $-6.2 \%$ & $-6.2 \%$ & $-7.5 \%$ & $-8.9 \%$ & $-6.2 \%$ \\
\hline HS-10 & $-10.9 \%$ & $-6.9 \%$ & $-8.0 \%$ & $-6.9 \%$ & $-6.9 \%$ \\
\hline HS-14 & $-8.2 \%$ & $-79.0 \%$ & $-56.5 \%$ & $-34.6 \%$ & $-7.6 \%$ \\
\hline HS-18 & $-46.8 \%$ & $-69.1 \%$ & $-81.6 \%$ & $-79.1 \%$ & $-8.0 \%$ \\
\hline HS-15 & $-9.0 \%$ & $-65.6 \%$ & $-60.7 \%$ & $-40.2 \%$ & $-9.0 \%$ \\
\hline HS-1 & $-9.5 \%$ & $-38.6 \%$ & $-73.6 \%$ & $-69.2 \%$ & $-11.1 \%$ \\
\hline HS-21 & $-14.6 \%$ & $-14.3 \%$ & $-73.0 \%$ & $-59.5 \%$ & $-14.3 \%$ \\
\hline HS-20 & $-14.8 \%$ & $-14.8 \%$ & $-33.0 \%$ & $-31.5 \%$ & $-14.8 \%$ \\
\hline HS-26 & $-21.2 \%$ & $-21.2 \%$ & $-42.9 \%$ & $-42.6 \%$ & $-21.2 \%$ \\
\hline HS-16 & $-26.7 \%$ & $-41.0 \%$ & $-49.8 \%$ & $-43.8 \%$ & $-25.2 \%$ \\
\hline HS-11 & $-25.4 \%$ & $-66.8 \%$ & $-45.8 \%$ & $-40.7 \%$ & $-26.6 \%$ \\
\hline HS-27 & $-12.7 \%$ & $-12.7 \%$ & $-21.3 \%$ & $-20.6 \%$ & $-27.9 \%$ \\
\hline HS-8 & $-31.3 \%$ & $-19.0 \%$ & $-83.7 \%$ & $-76.0 \%$ & $-28.2 \%$ \\
\hline HS-13 & $-27.1 \%$ & $-27.1 \%$ & $-36.5 \%$ & $-37.3 \%$ & $-31.8 \%$ \\
\hline HS-6 & $-33.3 \%$ & $-83.1 \%$ & $-71.6 \%$ & $-56.9 \%$ & $-33.3 \%$ \\
\hline HS-19 & $-33.4 \%$ & $-33.4 \%$ & $-54.4 \%$ & $-49.3 \%$ & $-33.4 \%$ \\
\hline HS-2 28 & $-35.2 \%$ & $-58.2 \%$ & $-70.5 \%$ & $-55.4 \%$ & $-35.2 \%$ \\
\hline$-39.3 \%$ & $-30.9 \%$ & $-30.9 \%$ & $-32.0 \%$ & $-42.4 \%$ \\
\hline$-30.6 \%$ & $-50.7 \%$ & $-16.1 \%$ & $-18.0 \%$ & $-44.8 \%$ \\
\hline
\end{tabular}

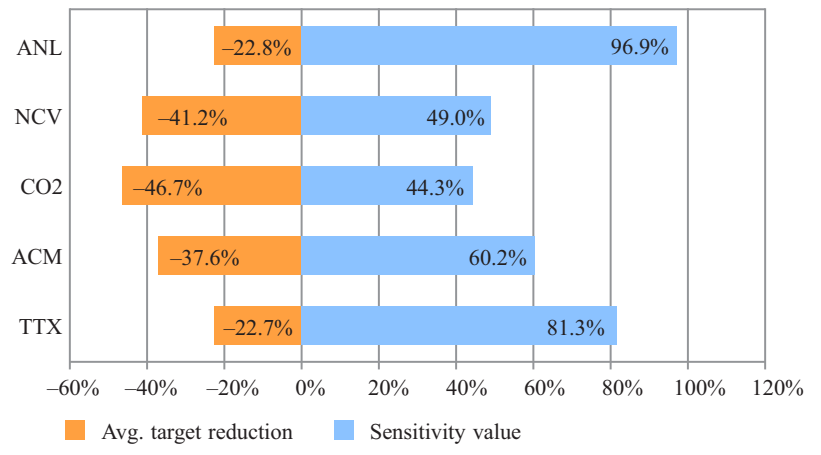

Fig. 3. Sensitivity analysis vs. average target reduction (\%)

get reduction (\%) values. In this regard, the sensitivity results enable us to understand the magnitude of change in the efficiency score as a result of the relative change in the input variables (social and environmental indicators).

For example, TTX was found to have the highest sensitivity ratio for HS-1 (93\%). This was followed by $\mathrm{ACM}, \mathrm{CO} 2$, and $\mathrm{NCV}$, respectively $(33 \%, 25 \%$, and $29 \%$ ). It is important to note that ANL and TTX were found to have the highest average sensitivity ratio for the selected highway sections. The high sensitivity of this indicators means that a small reduction would have a higher impact on the overall socio-eco-efficiency compared to other indicators. On the other hand, the average target reductions represent a reverse trend compared to sensitivity values. The greatest reductions were suggested on $\mathrm{CO}_{2}(46.7 \%)$ and $\mathrm{NCV}(41.2 \%)$, which indicated relatively smaller sensitivity values. This result provides significant insights about the research conducted. For inefficient states to become $100 \%$ efficient, smaller reductions in TTX and ANL can have more significant improvement on the socio-economic efficiency scores.

\section{Conclusions}

In this paper, a DEA based sustainability assessment tool is developed to evaluate highways. The model used economic, social, and environmental indicators to calculate sustainability performance and result in scores for Oregon state highways. Even though, restricting the scope of the sustainability performance assessment to highways rather than the entire region that include the rural roadways provides a limited understanding about the overall sustainability problem; it is still very important for the United States to address such comparative sustainability assessment framework since U.S. roadway transportation is heavily based on highways and the vast majority of investments are being made on the interstate highways by the federal and state government transportation agencies. On the other hand, considering the heavy use of passenger cars and trucks on highways, which is a typical transport option for Americans, current scope of the study still addresses an important issue for the regional agencies and states' transportation departments.

Seven sustainability goals that pertain to sustainability were utilized: improve freight transport, main- 
tain highway system quality, improve mobility, improve safety, reduce adverse human health impacts, reduce greenhouse effect and reduce traffic noise. Results from the model showed that HS-30, HS-3, HS-22, HW-5, HS29, HS-24, HS-9, HS- 12 and HS-17 were $100 \%$ sustainable. Percent improvement analysis was carried out to find out the amount of reduction needed in the social and environmental parameters to reach $100 \%$ sustainability. Results of percent improvement analysis indicated that $22 \%$ to $47 \%$ reductions are required to be achieved on negative social and environmental impacts for the inefficiency highway sections to be $100 \%$ efficient while keeping the economic indicators the same. In addition, sensitivity analysis was conducted to understand how significant the different values of input parameters impacted the socio-eco-efficiency score of each highway section. An average of $44 \%$ to $97 \%$ sensitivity range is observed on the highway sections depending on the input variable.

For a successful policy implication towards improving highway sustainability, it is important for federal and state agencies to consider the highway sustainability problem from a "systems thinking perspective". In this regard, systems thinking can be considered as a policy making approach to improve the highway system sustainability, which views the sub-problems such as congestion, air pollution, and noise as parts of the overall system. It is important to implement policies within an integrated "holistic" framework, rather than reacting to specific sub problem, to not to contribute to development of unintended consequences as a result of imbalanced policy actions. Such an integrated framework that is based on the belief that the sub-problems of a system can be best understood in the context of relationships with each other and with other sub-problems. Therefore, it is crucial to implement hybrid policy implications to improve the sustainability performance of highways, which was also stated in an earlier work (Egilmez, Tatari 2012).

To improve mobility, safety and reduce the environmental burdens, hybrid implementation of green vehicles, public transportation and car pooling, fuel efficiency improvement, intelligent transportation systems (Intelligent Transportation Systems Benefits, Costs, Deployment and Lessons Learned, 2008) have to be considered simultaneously prior to taking action. In this regard, the results of sensitivity analysis reveal significant insights to federal and state government agencies to be used for prioritizing the policy areas. In this regard, TTX and ANL are found to be the most sensitive indicators for sustainability performances, which also require lower target reductions for inefficient highways to reach $100 \%$ efficiency frontier.

Additionally, with regard to construction and management, the system's thinking also need to be integrated. In this regard, life cycle sustainability performance could bring significant insights to policy making in pavement construction. In this regard, recent works such as Tatari and Kucukvar (2012) can be used as a detailed policy guidance in constructing transportation systems with reduced environmental burden and maintained social and economical benefits. Then, current approach can be re-utilized for pair wise and time series-based benchmarking purposes to envision the improvements in the three dimensions of sustainability.

The analysis of DEA results could be very helpful to state highway agencies to compare the relative sustainability of highways. However, it should be noted that DEA compares the sustainability of highway sections by analyzing other sections in the data set. This is a major drawback of DEA, since the sustainability scores are relative to the sustainability of the highway sections in the data set. Also, accuracy of the results depends on the accuracy of the data extracted. Another limitation is that, as one of the indicators, TTX represents the congestion. Since some of the highway sections are built in comparably secluded areas, other performance measures related to congestion would bring more insights to results, which can be considered as a future work. All in all, taking these limitations into consideration, the developed DEA-based sustainability assessment model can be used by transportation agencies to evaluate highways within their jurisdiction. It not only provides immediate assessment of sustainability but also helps provide feedback to actually develop more sustainable planning goals in the future. In future work, enlargement of the data set to include most state-wide highway inventory is planned in order to produce more generalized sustainability scores. This highway inventory could extend to include different states and larger regions, as well.

\section{References}

Abbott, P. G.; Nelson, P. M. 2002. Converting the UK traffic noise index LA10,18h to EU noise indices for noise mapping. Transport Research Laboratory, UK.

Amekudzi, A. A.; Jotin Khisty, C.; Khayesi, M. 2009. Using the sustainability footprint model to assess development impacts of transportation systems, Transportation Research Part A: Policy and Practice 43(4): 339-348. http://dx.doi.org/10.1016/j.tra.2008.11.002

Banker, R. D.; Charnes, A.; Cooper, W. W. 1984. Some models for estimating technical and scale inefficiencies in data envelopment analysis, Management Science 30(9): 10781092. http://dx.doi.org/10.1287/mnsc.30.9.1078

Barba-Gutiérrez, Y.; Adenso-Díaz, B.; Lozano, S.; 2009. Eco-efficiency of electric and electronic appliances: a data envelopment analysis (DEA), Environmental Modeling and Assessment 14(4): 439-447.

http://dx.doi.org/10.1007/s10666-007-9134-2

Barbier, E. B. 2009. The concept of sustainable economic development, Environmental Conservation 14(02): 101-110. http://dx.doi.org/10.1017/S0376892900011449

Callens, I.; Tyteca, D. 1999. Towards indicators of sustainable development for firms: a productive efficiency perspective, Ecological Economics 28(1): 41-53. http://dx.doi.org/10.1016/S0921-8009(98)00035-4

Charnes, A.; Cooper, W.; Rhodes, E. 1978. Measuring the efficiency of decision making units, European Journal of Operational Research 2(6): 429-444. http://dx.doi.org/10.1016/0377-2217(78)90138-8 
Cook, W. D.; Kazakov, A.; Persaud, B. 2001. Prioritising highway accident sites: a data envelopment analysis model, Journal of the Operational Research Society 52(3): 303309. http://dx.doi.org/10.1057/palgrave.jors.2601078

Ding, G. K. C. 2008. Sustainable construction - the role of environmental assessment tools, Journal of Environmental Management 86(3): 451-464.

http://dx.doi.org/10.1016/j.jenvman.2006.12.025

Egilmez, G.; Tatari, O. 2012. A dynamic modeling approach to highway sustainability: strategies to reduce overall impact, Transportation Research Part A: Policy and Practice 6(7): 1086-1096.

http://dx.doi.org/10.1016/j.tra.2012.04.011

Färe, R.; Grosskopf, S.; Hernandez-Sancho, F. 2004. Environmental performance: an index number approach, Resource and Energy Economics 26(4): 343-352. http://dx.doi.org/10.1016/j.reseneeco.2003.10.003

Färe, R.; Grosskopf, S.; Lovell, C.; Pasurka, C. 1989. Multilateral productivity comparisons when some outputs are undesirable: a nonparametric approach, The Review of Economics and Statistics 71(1): 90-98.

Graedel, T. E.; Allenby, B. R. 2009. Industrial ecology and sustainable engineering. Prentice Hall.

Hall, R. P. 2006. Understanding and applying the concept of sustainable development to transportation planning and decision-making in the US. Massachusetts Institute of Technology, USA.

Intelligent transportation systems. Benefits, costs, deployment, and lessons learned. 2008. U.S. Department of Transportation, Research and Innovative Technology Administration.

Jeon, C. M.; Amekudzi, A. 2005. Addressing sustainability in transportation systems: definitions, indicators, and metrics, Journal of Infrastructure Systems 11: 31-50.

http://dx.doi.org/10.1061/(ASCE)1076-0342(2005)11:1(31)

Jeon, C. M.; Amekudzi, A.; Guensler, R. L. 2007. Evaluating transportation system sustainability: Atlanta metropolitan region, in Proceedings of the 2007 Transportation Research Board Annual Meeting, 22 January 2007, Washington, DC.

Johnston, R. A. 2008. Indicators for sustainable transportation planning, Transportation Research Record: Journal of the Transportation Research Board 2067(17): 146-154. http://dx.doi.org/10.3141/2067-17

Kibert, C. 2008. Sustainable construction: green building design and delivery. Wiley.

Korhonen, P. J.; Luptacik, M. 2004. Eco-efficiency analysis of power plants: An extension of data envelopment analysis, European Journal of Operational Research 154(2): 437446. http://dx.doi.org/10.1016/S0377-2217(03)00180-2

Kuosmanen, T.; Kortelainen, M.; 2005. Measuring eco-efficiency of production with data envelopment analysis, Journal of Industrial Ecology 9(4): 59-72. http://dx.doi.org/10.1162/108819805775247846

Litman, T. 2005. Well measured: developing indicators for comprehensive and sustainable transportation planning. Victoria Transportation Policy Institute, Victoria, British Columbia, Canada.

Litman, T. 2007. Developing indicators for comprehensive and sustainable transport planning, Transportation Research Record: Journal of the Transportation Research Board 2017: 10-15

López, E.; Monzón, A. 2010. Integration of sustainability issues in strategic transportation planning: a multi-criteria model for the assessment of transport infrastructure plans, Comput-
er-Aided Civil and Infrastructure Engineering 25(6): 440 451. http://dx.doi.org/10.1111/j.1467-8667.2010.00652.x

Mihelcic, J. R.; Crittenden, J. C.; Small, M. J.; Shonnard, D. R.; Hokanson, D. R.; Zhang, Q.; Chen, H.; Sorby, S. A.; James, V. U.; Sutherland, J. W. 2003. Sustainability science and engineering: the emergence of a new metadiscipline, Environmental Science and Technology 37(23): 5314-5324. http://dx.doi.org/10.1021/es034605h

National Science Technology Council. 2008. Scientific assessment of the effects of global change on the United States. National Science and Technology Council, Committee on Environment and Natural Resources.

ODOT. 2008. 2008 Oregon crash rate tables. Oregon Department of Transportation.

ODOT. 2010. State of Oregon: Highway. Oregon Department of Transportation.

Ozbek, M. E.; Garza, J. M.; Triantis, K. 2010. Efficiency measurement of bridge maintenance using data envelopment analysis, Journal of Infrastructure Systems 16(1): 31-39. http://dx.doi.org/10.1061/(ASCE)1076-0342(2010)16:1(31)

Ramani, T.; Zietsman, J.; Eisele, W.; Rosa, D.; Spillane, D.; Bochner, B. 2008. Developing sustainable transportation performance measures for TXDOT's strategic plan. Technical report. Texas Transportation Institute, College Station, Tex, USA.

Richardson, B. C. 2005. Sustainable transport: analysis frameworks, Journal of Transport Geography 13(1): 29-39. http://dx.doi.org/10.1016/j.jtrangeo.2004.11.005

Sarkis, J. 2007. Preparing your data for DEA, in Modeling data irregularities and structural complexities in data envelopment analysis. Springer, 305-320.

Schrank, D.; Lomax, T.; 2009. 2009 urban mobility report. Texas Transportation Institute, The Texas A\&M University System.

Shcherbakova, N. 2010. The efficiency assessment of big cities social and economic development: a system dynamics approach. St. Petersburg State Polytechnical University, Department of Economics and Management, Russia.

Tatari, O.; Kucukvar, M. 2012. Eco-efficiency of construction materials: data envelopment analysis, Journal of Construction Engineering and Management 138(6): 733-741. http://dx.doi.org/10.1061/(ASCE)CO.1943-7862.0000484

Thanassoulis, E. 2001. Introduction to the theory and applicatins of data envelopment analysis: a foundation text with integrated software. New York, NY: Springer. http://dx.doi.org/10.1007/978-1-4615-1407-7

Triantis, K. P. 2004. Engineering applications of data envelopment analysis, in Handbook on data envelopment analysis. Elsevier, 401-441.

Tyteca, D. 1997. Linear programming models for the measurement of environmental performance of firms - concepts and empirical results, Journal of Productivity Analysis 8(2): 183-197. http://dx.doi.org/10.1023/A:1013296909029

Tyteca, D. 1999. Sustainability indicators at the firm level, Journal of Industrial Ecology 2(4): 61-77. http://dx.doi.org/10.1162/jiec.1998.2.4.61

USDOT. 2002. Highway economic requirements system - state version. Technical report. U.S. Department of Transportation, Washington, DC.

USDOT. 2008. 2008 status of the nation's highways, bridges, and transit: conditions and performance. Report to Congress. 
Omer TATARI. Dr, serves as an Assistant Professor in the Department of Civil, Environmental, and Construction Engineering at University of Central Florida. His research focuses on systems analysis of the social, environmental, and economic aspects of engineered systems. Dr. Tatari is the author of over fifty scientific publications in the areas of sustainable transportation, built environment sustainability, and life cycle assessment.

Gokhan EGILMEZ. Dr, serves as an Assistant Professor in the Department of Industrial and Manufacturing Engineering at North Dakota State University. His research interests include life cycle sustainability assessment of socio-economic and environmental aspects of engineered systems and developing decision support approaches such as dynamic simulation modeling, optimization, statistical analysis and data mining. He has over ten scientific publications in the areas of decision modeling for sustainable manufacturing, environmental life cycle assessment, sustainable transportation, transportation safety and manufacturing system design and control.

Dhruva KURMAPU. She received her Master of Science degree from Ohio University. Research interests include highway sustainability, sustainable engineering, and operations research. 